\title{
Kerentanan Acanthamoeba spp. terhadap Larutan Disinfektan Pelbagai Guna Kanta Sentuh
}

(Susceptibility of Acanthamoeba spp. towards Contact Lens Multi-purpose Disinfecting Solution)

\author{
Mohamed Kamel AbD GHAni*, Syamimi OMar, ANiSAH Nordin, Yusof Suboh, Noraina Ab RaHim, \\ WAN OMAR ABDULLAH \& NORAZAH AHMAD
}

\begin{abstract}
ABSTRAK
Acanthamoeba spp. adalah patogenik dan berpotensi menyebabkan kebutaan melalui penyakit yang dikenali sebagai keratitis Acanthamoeba (AK) khususnya dalam kalangan pemakai kanta sentuh. Kajian ini dijalankan untuk menilai kerentanan sista Acanthamoeba terhadap larutan disinfektan pelbagai guna kanta sentuh dengan menggunakan empat isolat Acanthamoeba iaitu dua isolat klinikal; HUKM 38, HKL 10 dan dua persekitaran; PBA 46 dan PBA 42. Lima jenis larutan disinfektan pelbagai guna; Complete ${ }^{\circledR}$, Renu$^{\circledR}$ fresh $^{T M}$, RevitaLens OcuTec $^{\circledR}$, Opti-Fre ${ }^{\circledR}$ Express $^{\circledR}$ dan Solo Care Aqua ${ }^{\circledR}$ telah diuji ke atas sista Acanthamoeba tersebut. Masa rendaman adalah berdasarkan masa yang disyorkan oleh pengeluar (4 jam dan 6 jam), 8 jam dan 24 jam. Setiap campuran sista dan larutan disinfektan kanta sentuh dipindahkan ke atas agar tanpa nutrien yang dilapisi Escherichia coli. Plat agar diperhatikan di bawah mikroskop songsang setiap hari sehingga hari ke-14 untuk melihat kehadiran trofozoit. Kelima-lima larutan disinfektan pelbagai guna kanta sentuh tidak efektif membunuh kesemua isolat sista Acanthamoeba yang diuji. Ini menunjukkan bahawa kebanyakan larutan disinfektan pelbagai guna kanta sentuh tidak mempunyai aktiviti anti-Acanthamoeba yang sangat diperlukan bagi mencegah jangkitan keratitis Acanthamoeba dalam kalangan pengguna kanta sentuh.
\end{abstract}

Kanta kunci: Acanthamoeba; keberkesanan; larutan disinfektan pelbagai guna kanta sentuh; Malaysia

ABSRACT

Acanthamoeba spp. are pathogenic to humans, causing potentially blinding infection of the cornea known as Acanthamoeba keratitis (AK) especially among contact lens wearers. This study was undertaken to investigate the susceptibility of Acanthamoeba cyst to multi-purpose contact lens disinfecting solution on four Acanthamoeba isolates comprising two clinical isolates; HUKM 38, HKL 102 and two environmental isolates; PBA 46 and PBA 42. Five multi-purpose contact lens disinfecting solutions; Complete ${ }^{\circledR}$, renu ${ }^{\circledR}$ fresh $^{T M}$, RevitaLens OcuTec ${ }^{\circledR}$, Opti-Free $^{\circledR}$ Express $^{\circledR}$ and Solo Care Aqua ${ }^{\circledR}$ were tested on cysts of the four Acanthamoeba isolates. The soaking times were based on manufacturer's recommendations $(4$ and $6 \mathrm{~h}$ ) and 8 and $24 \mathrm{~h}$. Each mixture of the cysts and disinfecting solution was transferred onto non-nutrient agar seeded with Escherichia coli. The agar plates were examined under inverted microscope daily until day 14 to detect the presence of Acanthamoeba trophozoites. All 5 multi-purpose contact lens disinfecting solutions tested were ineffective to kill all Acanthamoeba cyst isolates tested. This indicates that most multi-purpose contact lens disinfecting solutions do not have anti-Acanthamoeba activity necessary to prevent keratitis amongst contact lens wearers.

Keywords: Acanthamoeba; contact lens multi-purpose disinfecting solution; effectiveness; Malaysia

\section{PENDAHULUAN}

Acanthamoeba adalah genus protozoa hidup bebas yang ditemui dalam pelbagai habitat semula jadi termasuk air, tanah dan udara (Kumar \& Lloyd 2002). Acanthamoeba mempunyai dua peringkat hidup iaitu peringkat trofozoit dan peringkat sista. Sista adalah peringkat diferensiasi sel daripada trofozoit apabila keadaan sekeliling menjadi tidak sesuai seperti ketiadaan makanan, suhu yang terlalu sejuk atau kering (Rocha-Azevedo et al. 2009). Acanthamoeba boleh dibahagikan kepada tiga kumpulan morfologi iaitu kumpulan I, kumpulan II dan kumpulan III. Pembahagian kumpulan ini adalah berdasarkan saiz dan bentuk sista (Marciano-Cabral \& Cabral 2003).
Acanthamoeba boleh menyebabkan pelbagai jenis penyakit, antaranya Granulamatous Amoebic Encephalitis (GAE), cutaneous acanthamoebiasis dan Keratitis Acanthamoeba (AK) (Johnston et al. 2009; Rocha-Azevedo et al. 2009). Menurut kajian Kamel dan Norazah (1995), kes pertama keratitis Acanthamoeba yang berlaku di Malaysia telah dilaporkan pada tahun 1995. Kes ini melibatkan seorang wanita yang memakai kanta sentuh. Bilangan kes AK terus meningkat di Malaysia dan kebanyakannya melibatkan pengguna kanta sentuh (Kamel et al. 2005, 2003).

Keratitis Acanthamoeba adalah infeksi kornea yang jarang berlaku tetapi merupakan suatu penyakit serius serta 
mempunyai potensi mengancam penglihatan terutamanya dalam kalangan pengguna kanta sentuh (Rocha-Azevedo et al. 2009; Ueki et al. 2009). Menurut kajian Khan (2006), antara faktor yang terlibat dalam proses menyebabkan jangkitan keratitis Acanthamoeba adalah: pemakaian kanta sentuh terlalu lama; amalan kebersihan yang rendah; tidak membersihkan kanta sentuh dengan betul; pembentukan biofilem pada kanta sentuh; dan pendedahan kanta sentuh kepada air yang tercemar.

Keratitis Acanthamoeba yang melibatkan pengguna kanta sentuh semakin meningkat. Hal ini adalah disebabkan oleh kemasukan bendasing secara sentuhan terus ke dalam mata. Infeksi yang melibatkan kanta sentuh ini biasanya disebabkan oleh cara penjagaan kanta sentuh yang salah, kurang kebersihan dalam penggunaan kanta sentuh, menggunakan air paip untuk membasuh kanta sentuh, menggunakan larutan disinfektan yang tamat tempoh dan tidak membersihkan bekas penyimpanan kanta sentuh dengan betul.

Larutan kanta sentuh adalah penting dalam penggunaan kanta sentuh. Larutan ini mampu membunuh patogen yang melekat pada kanta sentuh. Terdapat dua jenis larutan disinfeksi kanta sentuh yang terdapat dalam sistem larutan kanta sentuh iaitu: larutan kanta sentuh pelbagai guna; dan larutan kanta sentuh sistem hidrogen peroksida. Larutan kanta sentuh pelbagai guna merupakan larutan disinfeksi yang digunakan sebagai disinfektan, membersihkan dan untuk merendam kanta sentuh semasa penyimpanannya. Sistem hidrogen peroksida menunjukkan aktiviti antiameba yang sangat tinggi berbanding larutan disinfetan kanta sentuh pelbagai guna (Hughes et al. 2003). Disebabkan oleh meningkatnya bilangan kes keratitis Acanthamoeba di Malaysia dalam kalangan pengguna kanta sentuh, maka adalah perlu bagi kajian ini dijalankan untuk mengkaji kesan beberapa jenis larutan disinfektan kanta sentuh yang ada dalam pasaran terhadap sista Acanthamoeba yang dipencilkan daripada kes keratitis dan persekitaran di Malaysia.

\section{BAHAN DAN KAEDAH}

\section{SUMBER ACANTHAMOEBA SPP.}

Acanthamoeba spp. diperoleh dari Makmal Acanthamoeba, Fakulti Perubatan, Universiti Kebangsaan Malaysia. Kesemua empat isolat ini termasuklah dua daripada isolasi klinikal; HKL 102 dan HUKM 38 serta dua daripada isolasi persekitaran; PBA 42 dan PBA 46. Acanthamoeba yang telah disubkultur di atas agar bukan nutrien yang dilapisi E.coli matian haba dibiarkan selama beberapa hari supaya trofozoit Acanthamoeba bertukar menjadi sista.

\section{LARUTAN PELBAGAI GUNA KANTA SENTUH}

Larutan disinfektan kanta sentuh yang digunakan adalah Opti-Free ${ }^{\circledR}$ Express (Alcon, USA), Complete ${ }^{\circledR}$ MultiPurpose Solution (AMO, USA), Renu ${ }^{\circledR}$ fresh $^{\text {TM }}$ Multi-
Purpose Solution (Bausch \& Lomb, USA), RevitaLens Ocutec ${ }^{\circledR}$ Multi-Purpose Disinfecting Solution (AMO, USA) dan Solo Care Aqua ${ }^{\circledR}$. Kesemua larutan ini telah dibeli dari farmasi dan telah dipastikan diguna sebelum tarikh luputnya.

\section{KAEDAH PEMPROSESAN SAMPEL}

Ujian yang dijalankan adalah berdasarkan kaedah filtrasi-kultur Narasimhan et al. (2002). Ujian kerentanan dijalankan dalam tiub ependof $1.5 \mathrm{~mL}$. $1 \mathrm{~mL}$ larutan disinfektan kanta sentuh dimasukkan ke dalam setiap tiub ependof. $10 \mu \mathrm{L}$ suspensi sista $1 \times 10^{6}$ dipipetkan ke dalam tiub ependof yang mengandungi $1 \mathrm{~mL}$ larutan disinfektan kanta sentuh. Tiub ependof kemudian disusun dalam rak mikrotiub dan diletakkan ke dalam laci untuk memberikan kesan gelap seperti bekas penyimpanan kanta sentuh. Kawalan positif disediakan dengan suspensi sista dengan 3\% hidrogen peroksida dan kepekatan ini dapat membunuh parasit. Kawalan positif lain pula mengandungi sista dalam salin ameba untuk memastilan bahawa sista Acanthamoeba yang digunakan dalam ujian ini berdaya hidup dan boleh muncul dalam bentuk trofozoit. Bagi kawalan negatif, larutan PAS dan larutan disinfektan kanta sentuh akan dibiarkan sendirian untuk memastikan tiada sebarang kontaminasi yang berlaku.

Selepas masa rendaman yang ditetapkan iaitu 4, 6, 8 dan 24 jam, $100 \mu \mathrm{L}$ sampel dipipetkan ke atas piring agar tanpa nutrien yang dilapisi dengan $E$. coli matian haba. Piring petri kemudiannya diinkubasi pada suhu $30^{\circ} \mathrm{C}$ selama 3 hari. Plat media diperiksa untuk melihat kehadiran trofozoit Acanthamoeba di bawah mikroskop songsang selama 14 hari. Kehadiran trofozoit yang muncul daripada peringkat sista menunjukkan ketakberkesanan disinfektan kanta sentuh yang digunakan dan keputusan ujian aktiviti anti-Acanthamoeba direkodkan sebagai keputusan negatif.

\section{KEPUTUSAN}

Kesemua larutan disinfektan pelbagai guna kanta sentuh dalam kajian ini tidak berkesan membunuh sista Acanthamoeba spp. Setelah sista didedahkan kepada larutan disinfektan pelbagai guna kanta sentuh (Complete ${ }^{\circledR}$, renu ${ }^{\circledR}$ fresh ${ }^{\mathrm{TM}}$, RevitaLens OcuTec ${ }^{\circledR}$, Opti-Free ${ }^{\circledR}$ Express $^{\circledR}$ dan Solo Care Aqua ${ }^{\circledR}$ ) selama masa yang disyorkan oleh pengeluar; 4 dan 6 jam serta didedahkan sehingga 8 dan 24 jam tiada dan sebarang aktiviti anti-Acanthamoeba yang ditunjukkan terhadap keempat-empat isolate (Jadual 1). Kawalan positif sista dan 3\% hidrogen peroksida dapat membunuh kesemua sista manakala kawalan positif sista dalam salin ameba (PAS) menunjukkan bahawa sista Acanthamoeba yang digunakan dalam ujian ini menjadi trofozoit tanpa sebarang rencatan. (Jadual 2). Kawalan negatif merupakan larutan PAS dan larutan disinfektan kanta sentuh yang dibiarkan tanpa sista dan ia menunjukkan tiada sebarang kontaminasi yang berlaku (Jadual 2). 
JADUAL 1. Keputusan kajian kerentanan Acanthamoeba spp. terhadap larutan kanta sentuh Complete ${ }^{\circledR}$, Renu ${ }^{\circledR}$ fresh $^{\mathrm{TM}}$, RevitaLens OcuTec ${ }^{\circledR}$, Opti-Free ${ }^{\circledR}$ Express $^{\circledR}$ dan Solo Care Aqua ${ }^{\circledR}$

\begin{tabular}{lcccc}
\hline Strain & 4 Jam & 6 Jam* & 8 Jam & 24 Jam \\
\hline HUKM38 & - & - & - & - \\
HKL102 & - & - & - & - \\
PBA46 & - & - & - & - \\
PBA42 & - & - & - & - \\
\hline Petunjuk: & \\
$-\quad$ tiada sebarang aktiviti anti-Acanthamoeba yang berlaku & &
\end{tabular}

JADUAL 2. Keputusan kawalan positif bagi ujian keberkesanan larutan disinfektan pelbagai guna kanta sentuh

\begin{tabular}{lcccc}
\hline Strain & Suspensi sista & $3 \% \mathrm{H}_{2} \mathrm{O}_{2}$ & Larutan PAS & Larutan disinfektan \\
\hline HUKM38 & + & - & $\mathrm{x}$ & $\mathrm{x}$ \\
$\mathrm{HKL102}$ & + & - & $\mathrm{X}$ & $\mathrm{X}$ \\
$\mathrm{PBA} 46$ & + & - & $\mathrm{X}$ & $\mathrm{X}$ \\
$\mathrm{PBA} 42$ & + & & $\mathrm{X}$ \\
\hline $\mathrm{x}$ & Tiada kehadiran trofozoit dan sista Acanthamoeba & & \\
$+\quad$ Kehadiran trofozoit dan sista Acanthamoeba & & \\
$-\quad$ Tiada kehadiran trofozoit Acanthamoeba & & \\
$\mathrm{H}_{2} \mathrm{O}_{2}$ Hidrogen peroksida & & \\
PAS Page amebic saline & &
\end{tabular}

\section{PERBINCANGAN}

Jangkitan keratitis disebabkan oleh Acanthamoeba semakin meningkat dalam kalangan pengguna kanta sentuh. Kes ini juga telah dilaporkan semakin meningkat dalam kalangan pengguna kanta sentuh di Malaysia. Jangkitan keratitis yang menyebabkan ulser kornea ini boleh menyebabkan parut signifikan pada kornea dan membawa pada kebutaan (Haliza et al. 2005).

Larutan disinfektan pelbagai guna kanta sentuh Complete tidak menunjukkan sebarang aktiviti antiAcanthamoeba walaupun setelah direndam selama 4 dan 6 jam (disyorkan oleh pengeluar), 8 dan 24 jam. Larutan pelbagai guna ini mengandungi polyhexamethylene biguanide (PHMB) $0.0001 \%$ sebagai bahan aktifnya. Kajian yang dijalankan oleh Niszl dan Markus (1998) telah menunjukkan bahawa larutan disinfektan pelbagai guna Complete ${ }^{\circledR}$ dengan $0.0001 \%$ PHMB tidak menunjukkan sebarang aktiviti anti-Acanthamoeba pada kesemua strain Acanthamoeba. PHMB adalah berkesan sebagai anti-mikrob pada kepekatan $200 \mathrm{mg} / \mathrm{L}(0.02 \%)$ apabila digunakan untuk merawat pesakit keratitis yang disebabkan oleh Acanthamoeba spp (Messick et al. 1999). Oleh itu, kepekatan yang rendah dalam larutan disinfektan ini mungkin tidak berkesan untuk membunuh sista.

Tiada sebarang aktiviti anti-Acanthamoeba yang ditunjukkan larutan disinfektan pelbagai guna Renu® fresh $^{\mathrm{TM}}$ terhadap kesemua strain sista Acanthamoeba yang digunakan dalam kajian ini. Renu ${ }^{\circledR}$ fresh $^{\mathrm{TM}}$ mempunyai bahan aktif DYMED (polyaminopropyl biguanide) $0.0001 \%$. Dalam satu kajian lepas, tiada perbezaan statistik yang signifikan pada aktiviti anti-Acanthamoeba larutan
Bausch \& Lomb ReNu MultiPlus terhadap A. castellani, A. hatchetti dan A. polyphaga (Johnston et al. 2009).

Dalam kajian yang telah dijalankan oleh Kilvington et al. (2010), telah didapati bahawa larutan disinfektan pelbagai guna RevitaLens OcuTec $\AA$ menunjukkan aktiviti anti-Acanthamoeba yang efektif. Ia dapat membunuh sista dan trofozoit Acanthamoeba sehingga hampir $99.0 \%$. Bahan aktif yang terkandung di dalamnya terdiri daripada Alexidine $0.00016 \%$ dan Polyquaternium-1 (PQ-1) $0.0003 \%$. Alexidine adalah alkil antiseptik biguanide yang mempunyai aktiviti antimikrob. Namun, dalam kajian ini tiada sebarang aktiviti anti-Acanthamoeba yang dikesan dalam semua 4 isolat klinikal dan persekitaran setelah didedahkan selama 4 dan 6 jam (masa disyorkan oleh pengeluar), 8 dan 24 jam. Dalam kajian yang dijalankan oleh Codling et al. (2003) mendapati bahawa PQ-1 telah menunjukkan aktiviti anti-bakteria yang sangat tinggi berbanding sebagai anti-amoeba terhadap A. castellanii. Perbezaan strain Acanthamoeba yang diuji dalam kajian ini berbanding strain kajian oleh Kilvington juga mungkin memberikan keputusan yang berbeza.

Dalam kajian ini, sista Acanthamoeba telah didedahkan kepada larutan disinfektan pelbagai guna Opti-Free ${ }^{\circledR}$ Express ${ }^{\circledR}$ selama 4 dan 6 jam (masa yang disyorkan oleh pengeluar), 8 dan 24 jam. Keputusan mendapati tiada sebarang aktiviti anti-Acanthamoeba yang direkodkan berlaku. Bahan aktif yang terkandung dalam larutan disinfektan pelbagai guna ini adalah POLYQUAD $^{\circledR}$ (polidronium klorida) $0.001 \%$ dan ALDOX $^{\circledR}$ (myristamidopropyl dimethylamine) $0.0005 \%$. Kajian yang dijalankan oleh Kilvington et al. (2002) mendapati bahawa ALDOX ${ }^{\circledR}$ adalah efektif dan menunjukkan aktiviti 
anti-Acanthamoeba. Pelbagai isolat yang digunakan dalam kajian ini berbanding kajian lain mungkin menghasilkan keputusan yang berlainan.

Larutan disinfektan pelbagai guna Solo Care Aqua ${ }^{\circledR}$ yang mempunyai bahan aktif polyhexanide $0.001 \mathrm{mg} /$ $\mathrm{mL}$ telah gagal menunjukkan sebarang aktiviti antiAcanthamoeba walaupun setelah didedahkan selama 4 jam (masa yang disyorkan pengeluar), 6, 8 dan 24 jam dalam kajian ini. Kajian oleh Borazjani dan Kilvington (2005) memberikan keputusan larutan ini berjaya membunuh trofozoit Acanthamoeba isolat I HG dan IV HG serta sista Acanthamoeba isolat I HG sahaja. Berdasarkan kajian terdahulu dapat diandaikan bahawa larutan Solo Care Aqua $^{\circledR}$ lebih berkesan membunuh trofozoit berbanding sista. Sista Acanthamoeba adalah sangat rintang terhadap bahan kimia, suhu yang melampau dan juga keadaan yang kritikal berbanding trofozoit (Niszl \& Markus 1998).

\section{KESIMPULAN}

Berdasarkan kajian ini, didapati bahawa larutan disinfektan kanta sentuh pelbagai guna yang diuji adalah tidak berkesan sebagai agen anti-Acanthamoeba. Ini memberi gambaran bahawa penggunaannya dalam kalangan pengguna kanta sentuh mungkin tidak dapat memberi perlindungan terhadap jangkitan keratitis Acanthamoeba. Pencarian larutan disinfektan kanta sentuh yang memberikan kesan anti-Acanthamoeba adalah penting diteruskan dalam usaha mencegah keratitis Acanthamoeba dalam kalangan pengguna kanta sentuh.

\section{RUJUKAN}

Borazjani, R.N. \& Kilvington, S. 2005. Efficacy of multipurpose solutions against Acanthamoeba species. Contact Lens and Anterior Eye 28(4): 169-175.

Codling, C.E., Maillard, J-Y. \& Russell, A.D. 2003. Aspects of the antimicrobial mechanisms of action of a polyquaternium and an amidoamine. Journal of Antimicrobial Chemotherapy 53: $1153-1158$.

Haliza, A.M., Saleha, A.M., Kamel, A.G.M., Anisah, N., Yusof, S. \& Norhayati, M. 2005. Punca infeksi Acanthamoeba spp. di kalangan pemakai kanta sentuh di Kuala Lumpur. Jurnal Sains Kesihatan Malaysia 3(2): 9-17.

Hughes, R.,Heaselgrave, W.\& Kilvington, S. 2003. Acanthamoeba polyphaga strain age and method of cyst production influence the observed efficacy of therapeutic agents and contact lens disinfectants. Antimicrobial Agent and Chemotherapy 47(10): 3080-3083.

Johnston, S.P., Sriram, R., Qvarnstrom, Y., Roy, S., Verani, J., Yoder, J., Lorick, S., Roberts, J., Beach, M.J. \& Visvesvara, G. 2009. Resistance of Acanthamoeba cysts to disinfection in multiple contact lens solutions. Journal of Clinical Microbiology 47(7): 2040-2045.

Kamel,A.G.M. \& Norazah,A. 1995. First case of Acanthamoeba keratitis in Malaysia. Transactions of the Royal Society of Tropical Medicine \& Hygiene 89: 652.

Kamel, A.G.M., Haniza, H., Anisah, N., Yusof, S., Faridah, H., Norhayati, M. \& Norazah, A. 2005. More Acanthamoeba keratitis cases in Malaysia. International Medical Journal 12(1): 7-9.
Kamel, A.G.M., Anisah, N., Yusof, S., Faridah, H., Michael, I., Norhayati, M. \& Norazah, A. 2003. Acanthamoeba keratitis is not so rare in Malaysia. Medical Journal of Malaysia 58(Suppl. E), S150.

Khan, N.A. 2006. Acanthamoeba: Biology and increasing importance in human health. FEMS Microbiology Reviews 30: 564-595

Kilvington, S., Nikolic, M., Lam, A., Brady, N., Lonnen, J. \& Heaselgrave, W. 2010. Comparative antimicrobial efficacy of contact lens care solutions. Journal of Optometry (3)3: 134-142.

Kilvington, S., Hughes, R., Byas, J. \& Dart, J. 2002. Activities of therapeutic agents and myristamidopropyl dimethylamine against Acanthamoeba isolates. Antimicrobial Agent and Chemotherapy 46(6): 2007-2009.

Kumar, R. \& Lloyd, D. 2002. Recent advances in the treatment of Acanthamoeba keratitis. Clinical Infectious Diseases 35(4): 434-441.

Marciano-Cabral, F. \& Cabral, G. 2003. Acanthamoeba spp. as agents of disease in humans. Clin. Microbiol. Rev. 16: 273-307.

Messick, C.R., Pendland, S.L., Moshirfar, M., Fiscella, R.G., Losnedahl, K.J., Schriever, C.A. \& Schreckenberger, P.C. 1999. In-vitro activity of polyhexamethylene biguanide (PHMB) against fungal isolates associated with infective keratitis. Journal of Antimicrobial Chemotherapy 44(2): 297-298.

Narasimhan, S., Madhavan, H.N. \& Lily Therese, K. 2002. Development and application of an in vitro susceptibility test for Acanthamoeba species isolated from keratitis to polyhexamethylene biguanide and chlorhexidine. Journal of Cornea and External Disease 21(2): 203-205.

Niszl, I.A. \& Markus, M.B. 1998. Anti-Acanthamoeba activity of contact lens solutions. British Journal of Ophthalmology 82(9): 1033-1038.

Rocha-Azevedo, B.D., Tanowitz, H.B. \& Marciano-Cabral, F. 2009. Diagnosis of infections caused by pathogenic freeliving Amoebae. Interdiciplinary Perspectives on Infectious Diseases 2009: Article ID 251406.

Ueki, N., Eguchi, H., Oogi, Y., Shiota, H., Yamane, S., Umazume, H. \& Mizui, K. 2009. Three cases of Acanthamoeba keratitis diagnosed and treated in the early stage. The Journal of Medical Investigation 56: 166-169.

Mohamed Kamel Abd Ghani* \& Syamimi Omar Program Sains Bioperubatan, Fakulti Sains Kesihatan Universiti Kebangsaan Malaysia, Jalan Raja Muda Abdul Aziz 50300 Kuala Lumpur, Wilayah Persekutuan Malaysia

Anisah Nordin, Yusof Suboh, Noraina Ab Rahim Jabatan Parasitologi Perubatan, Fakulti Perubatan Universiti Kebangsaan Malaysia, Jalan Raja Muda Abdul Aziz 50300 Kuala Lumpur, Wilayah Persekutuan Malaysia

Wan Omar Abdullah

Jabatan Mikrobiologi dan Parasitologi Perubatan

Fakulti Perubatan dan Sains Kesihatan

Universiti Putra Malaysia

43400 Serdang, Selangor Darul Ehsan

Malaysia 
Norazah Ahmad

Unit Bakteriologi, Institut Penyelidikan Perubatan Jalan Pahang

50588 Kuala Lumpur, Wilayah Persekutan

Malaysia
*Corresponding author; email: mohamedkamela@yahoo.com

Received: 16 March 2014

Accepted: 2 June 2015 